DOI: $\underline{10.17805 / g g z .2020 .4 .3}$

\title{
Биосоциальность, генетизация, биоидентичность: социально-философский взгляд
}

\author{
О. В. Попова
}

Институт философии РАН, г. Москва,

\section{B. В. Попов}

Национальный исследовательский ядерный университет «МИФИ», г. Москва

В статье рассмотрены сочиально-философские проблемы развития феноменов биосоциальности, генетизации и биоидентичности. Продемонстрировано, что их присутствие в биополитической повестке - современный этап развития технонауки. Показан процесс формирования биосоииальных групп и дано общее представление о таких стадиях развития биосочиализаиии, как «коллективное вскипание» и «конвергенция усилий». Рассмотрен синдемический подход к проблеме биосочиальности, указывающий на релевантность лечения заболеваний с учетом сочиальной компоненты.

Проведен философский анализ проблем генетизации и неидентичности. Сделан вывод о том, что генетизаиия несет, с одной стороны, серьезный ятрогенный эффект, а с другой - порождает новый порядок соииальных отношений и новые способы координации членов общества и формирования коллективных идентичностей, а также формирует новую биополитическую повестку, в рамках которой учитывается особая активность пациентов, их способность к самоорганизации и отстаиванию своих прав.

Ключевые слова: биосочиальность; биоидентичность; биополитика; генетизачия; этика генетики; орфанные заболевания; медикализаџия; неидентичность; редкие заболевания

\section{Biosociality, Genetization, Bioidentity: A Social and Philosophical View}

\author{
O. V. Popova
}

Institute of Philosophy, Russian Academy of Sciences, Moscow,

$$
\text { V. V. Popov }
$$

National Research Nuclear University MEPhI, Moscow

\footnotetext{
* Исследование выполнено при финансовой поддержке РФФИ в рамках научного проекта № 20-011-00880.

The research was carried out with financial support from the Russian Foundation for Basic Research within the framework of the project No. 20-011-00880.
} 
The article deals with the socio-philosophical issues of the development of the phenomena of biosociality, genetization and bioidentity. It is demonstrated that their inclusion in the biopolitical agenda is the current stage in the development of technoscience. The authors represent the process of formation of biosocial groups and the outline of such developmental stages of biosocialization as "collective effervescence" and "convergence of efforts". The article considers the syndemic approach to the problem of biosociality, which indicates the relevance of treatment of diseases taking into account the social component.

The authors provide a philosophical analysis of the problems of genetization and non-identity. It is concluded that genetization has, on the one hand, a serious iatrogenic effect and, on the other hand, generates a new order of social relations and new ways of coordination of members of the society and the formation of collective identities, as well as a new biopolitical agenda, which takes into account a special activity of patients, their ability to self-organize and defend their rights.

Keywords: biosociality; bioidentity; biopolitics; genetization; ethics of genetics; orphan diseases; medicalization; non-identity; rare diseases

\section{ВВЕДЕНИЕ}

Развитие биотехнологий способствовало стремительной биосоциализации современного общества. Речь идет о кардинальном сдвиге в процессе восприятия человеком самого себя, о новых формах самопонимания, маркерами которого становятся понятия из области генетики. Влиянию генетической революции подверглась и современная философия.

В современный тезаурус все активнее проникают понятия из биологических наук, приставка био- также уже стала привычной данностью философского дискурсивного поля. Исследования биовласти и биополитики породили огромный пласт гуманитарных исследований и линий интерпретации. В данном контексте поле исследований, связанных с проблемой биосоциальности, биологической (генетической) идентичности, значительно меньше. Между тем эти феномены стали неотъемлемым признаком современной биополитики, порождая новые формы пространства включения и исключения, основанных на учете фенотипических и генетических признаков.

Биосоциальность и биоидентичность - феномены, описывающие важнейшие глобальные и локальные процессы развития современной биомедицины, которые определяют интересы все большего числа людей, рассматривающих собственную жизнь сквозь понятийно-категориальную сетку современной генетики и сложившихся под воздействием развития современных биотехнологий практик.

Концепт «биосоциальность» приобрел особую популярность в последнее десятилетие. Его появление связывают с именем П. Рабиноу, предсказав- 
шим появление новых форм коллективных идентичностей (биоидентичностей) и стратификации общества на основании биологических (генетических) показателей (Rabinow, 1992). Биосоциальность тесно связана с тенденцией биомедикализации общества. Чем больше имеется сведений о том, какое влияние оказывают гены на здоровье человека, траектории его жизни и поведение, тем более привлекательно использовать результаты биомедицинских открытий в социальной сфере.

Возможность обработки больших данных позволяет осуществлять масштабные проекты в области здравоохранения (например, персонализированную медицину) и выявлять связи между генетическими профилями и глобальными социоэкономическими показателями, идентифицировать конкретные болезни как характерные той или иной локальной группе. Такие современные проекты, как биобанки, уже невозможно рассматривать в отрыве от технонауки и социогуманитарной рефлексии о генетизации общества и формировании новых форм биоидентичности.

Генетизация оказывает, с одной стороны, серьезный ятрогенный эффект, a, с другой - порождает новый порядок общественных отношений и новые способы координации жизни социума и образования коллективных идентичностей, а также новую биополитическую повестку, в рамках которой учитывается особая активность пациентов, их способность к самоорганизации и отстаиванию своих прав. Так, пациенты с орфанными заболеваниями создают локусы биосоциальности (онлайн-сообщества, группы поддержки, фонды, волонтерские организации) с целью обеспечения собственных прав на охрану здоровья в условиях недостатка общественных ресурсов для обеспечения нужд здравоохранения.

Как происходит формирование нового биосоциального сообщества? Немаловажную роль здесь играет эмоциональная вовлеченность пациентов либо членов их семей, наличие общих разделяемых ценностей и общей заинтересованности в достижении определенных целей, например, получение финансирования от государства на покупку лекарственных средств или поиск спонсоров для создания онлайн-платформ по обмену пациентским опытом или же привлечение исследователей или фармкомпаний в целях проведения клинических исследований и разработки лекарственных препаратов.

Как происходит процесс биосоциализации?

На первой стадии очень важным становится эмоциональный накал. Это стадия «коллективного вскипания», характерная для различных феноменов, связанных с объединением людей, и проанализированная еще в 1912 г. Э. Дюркгеймом для описания вызывания взаимно разделяемых эмоций и необычного состояния общего возбуждения с исключительно сильными чувствами. Дюркгейм утверждал, что, когда люди выражают похожие виды 
эмоций, они становятся более сильными и перерастают в коллективную страсть (см.: Dimond, Bartlett, Lewis, 2015).

Несмотря на то, что сообщества объединяют индивидов с общей биологией, то, что их объединяет, не биологическое, а социальное. Коллективное выражение эмоций, например, на организуемых пациентами или их представителями конференциях приводит к формированию устойчивых социальных связей (ibid.).

На следующей стадии последовательно проводится в жизнь принцип конвергенции усилий. Он работает на разных уровнях общественной жизни, оказывая влияние и на формирование научного знания, и на процесс распространения клинических данных об орфанных заболеваниях, и на конкретные политические шаги по защите прав пациентов. Данный принцип также воздействует на процесс получения научного знания о редких нозологиях. Речь идет о гражданской науке - участии в клинических исследованиях, заказе определенных исследований группами больных и их представителями с характерным для этого процесса поиском спонсоров, т. е. о формировании научной повестки не только учеными, но прежде всего пациентскими организациями.

Биографический опыт орфанных пациентов разных стран мира отражает феномен сплетения процессов объективации пациента (осуществляющейся посредством формирования научной картины заболевания, изменяющейся под воздействием объективных данных о нем) и личной истории проживания этих данных, индивидуальной адаптации к полученной информации о болезни, задающей персональный экзистенциальный смысл генетически обусловленному диагнозу. Телесность пациента с тем или иным орфанным заболеванием, подвергающаяся на протяжении всей своей жизни биомедицинским манипуляциям и непрерывному технологическому воздействию, может рассматриваться в качестве гибридной формы, где сплетается органика, знание, технологии и экзистенциальный опыт персональной истории болезни.

Немаловажную роль в выстраивании конкретной биографической траектории играют семья и общественные организации, от которых исходит принцип конвергенции усилий. В этой связи особенное значение приобретает так называемый синдемический подход к проблеме биосоциальности (Singer et al., 2017).

Синдемиком называют совокупность двух или более заболеваний или других биологически опасных состояний. Наиболее часто они проявляются в условиях неравенства здравоохранения (health inequality) (бедности, стигматизации и т. д.). Поэтому население, благодаря таким взаимодействиям, испытывает дополнительные трудности при лечении. Классический пример синдемического подхода в области здравоохранения - это учет в прагматике медицинских действий эволюции того или иного заболевания. Например, 
распространению ВИЧ часто сопутствует развитие туберкулеза. При болезни Паркинсона многие пациенты страдают от излишней дневной сонливости. Следовательно, дополнительные усилия здравоохранения и материальные средства должны быть направлены на решение не только основной проблемы, но и связанных с нею сопутствующих проблем. По аналогии в отношении орфанных заболеваний зачастую наблюдается ситуация, когда заболевание (например, муковисцидоз) сопровождается развитием депрессии. Кроме необходимых курсов антибактериальной терапии больным требуется психологическая или психиатрическая помощь.

Однако в контексте синдемического подхода целесообразно лечить не только заболевание или сопутствующие ему негативные состояния и проблемы, здесь в целом важна социальная составляющая проблемы здоровья. Лечение заболеваний с учетом социальной компоненты является неотъемлемой частью перспективы синдемиков. Необходимость лечения ВИЧ сопряжена с борьбой с бедностью, это касается и многих других заболеваний, в том числе редких. Больной, страдающий недугом, имеет большие шансы на выживание и лучшее качество жизни, доступ к необходимым лекарствам при решении материальной проблемы. По аналогии решение экологических проблем или просветительство может оказать влияние на снижение частоты того или иного заболевания и на создание благоприятного фона (среды) для уже заболевших.

Проблема синдемиков может повлиять на политику в области здравоохранения, фокусируя внимание на том, как социальные, экономические и экологические факторы оказывают влияние на исследования здоровья при условии, что эти факторы не отделяются в процессе анализа возникшего заболевания (ibid.). В целом данный подход соответствует определению здоровья, принятому ВОЗ, в рамках которого подчеркивается, что здоровьем является состояние полного физического, душевного и социального благополучия, а не только отсутствие болезней и физических дефектов.

\section{ГЕНЕТИЗАЦИЯ И ПРОБЛЕМА НЕИДЕНТИЧНОСТИ}

Интенсивное развитие тенденции генетизации, характерной чертой которой стало утверждение власти генетики во многих сферах человеческой жизни (Lippman, 1992), актуализирует вопрос о ее границах. Как сохранить индивидуальную свободу в контексте разветвляющихся и всеохватывающих тенденций генетической медикализации? Как должен отстоять себя человек перед биотехнологической экспансией, посягающей на проникновение в самые интимные области человеческого существования, в частности, оказывающих влияние на формирование демографической политики в целом и конкретные решения в частной жизни, например, в репродуктивной сфере. 
В этой связи заслуживают внимания дискуссии, разворачивающиеся в философском дискурсе под общим зонтичным термином неидентичности. Дискурс о неидентичности, сложившийся в современной философии благодаря трудам Д. Парфита, Д. Бунина, Г. Кавки и других исследователей, затрагивает проблемы, значимые в своем прикладном применении. Речь идет о том, всякая ли жизнь стоит того, чтобы жить? Какое качество жизни делает ее стоящей ее проживания? Какую ответственность должны нести моральные агенты за жизнь другого существа, утратившего качество жизни, которое могло бы считаться приемлемым? Есть ли норма такого качества жизни? И кто является творцом этой нормы? Причиняет ли родитель вред ребенку, если была предоставлена информация о наличии патологий у плода или о рисках развития таких патологий после рождения? Наносит ли он вред, если не следует предписанным медицинским рекомендациям по предотвращению патологических состояний у будущего ребенка?

Проблема неидентичности поднимает вопрос о генетических предпосылках акта рождения, с одной стороны, об особой среде рождения, уникальной для каждого индивида, с другой, а также о неповторимой темпоральности, в которой только и мог родиться данный индивид. Смена этих основополагающих факторов приводит к рождению индивида, не идентичного данному, пусть и обладающему улучшенным качеством жизни, либо не обладающем существованием (фактом рождения). Что лучше - несовершенное существование (наполненное проблемами со здоровьем) или не-существование вообще?

Д. Парфит подчеркивает, что женщина, которая задает вопрос о том, кем бы она была, если бы ее «родители вступили в брак с другими людьми», игнорирует ответ — «никем» (Parfit, 1987: 351; здесь и далее пер. наш. - aвm.). Другие условия существования способствуют рождению других индивидов, не идентичных появившимся на свет здесь и сейчас. Парфит особым образом проблематизировал концепт «времени и манеры зачатия», чтобы показать, что личностная идентичность при всей ее изменчивости во времени опирается на некие базовые константы, изменение которых приводит к рождению совершенно другого индивида или не-рождению как таковому, к разрушению различных типов людей, определяемых вариациями исторических условий, цепочками событий, генетическими предрасположенностями, семейной микросредой, уровнем медицины, технологическим укладом и т. д. и т. п. Исследователь справедливо задает следующий вопрос: «...многие из нас могли бы действительно утверждать: “Даже если бы железные дороги и автомобили никогда не были изобретены, я бы все равно родился?”» (ibid.: 361). Один из наиболее обсуждаемых случаев постановки проблемы неидентичности связан с обсуждением вопроса об условиях, в которых рождается тот или иной ребенок. Они могут не соответствовать социальным ожиданиям, а сами родители 
подвергаться социальному остракизму. Например, речь идет о беременной 14летней девушке, которая дает существование своему ребенку, но при этом не способна дать (как это утверждает ее окружение) необходимые социальные условия его существования, то качество жизни, которое будет приемлемым для его роста и развития, т. е. дает ему «плохой старт в жизни». На моральных весах в этом случае оказываются различные, зачастую несовместимые ценности: ценность существования как такового и ценность существования, наполненного определенным качеством, заданного параметрами, одобренными в глазах социума и установками, связанными с представлением о будущем этого ребенка. Последние, как правило, подразумевают необходимость наличия образования и профессии у родителей, их финансовой независимости, т. е. определенных моральных условий, наполняющих акт существования неким качеством.

Однако в данный рациональный расклад социальных ожиданий вторгается категория темпоральности. Субъект, рожденный в других условиях (более благоприятных для него с точки зрения социума или даже самих родителей), будет однозначно другим субъектом, лишенным уникальности первого (что, конечно же, не отменяет его собственную уникальность). Д. Парфит в своих рассуждениях апеллирует к биологическим категориям: яйцеклетка, которую будет иметь эта девочка через 10 лет, будет другой яйцеклеткой, приготовленной для рождения совершенного другого ребенка. Либо же этой яйцеклетки может не быть вовсе (например, по состоянию здоровья).

И даже если иметь в виду новую биотехнологическую реальность с характерной для нее широко распространенной практикой криоконсервации гамет или человеческих эмбрионов, оказывается, что субъекта и его идентичность в буквальном и метафорическом смыслах слова «заморозить» нельзя. Изменение способа зачатия (например, использование экстракорпорального оплодотворения) способствует рождению неидентичного ребенка. Дело в том, что ребенок не определяется только своей генетической идентичностью, но и всеми условиями, с которыми он имеет дело как индивид с момента своего зачатия. При этом можно даже не упоминать про появляющиеся данные о патологиях у детей, зачатых с помощью ЭКО, или, по некоторым сведениям, наличии у них большей склонности к мутациям генетического аппарата. Речь не об этих суждениях, не имеющих под собой однозначной доказательной базы, а о том, что генетическая идентичность сплетается в узел с условиями и социальными установками и смыслами, дающими в совокупности старт развитию индивида или осуществляющими стигматизацию индивида.

В этой связи оценка одной и той же нозологии будет существенным образом отличаться. Так, синдром Дауна можно описывать исключительно в медицинских категориях, на основе которых могут делаться рекомендации о 
прерывании беременности. Но точно также в другой социальной оптике данный диагноз может быть представлен как индивидуальная особенность развития, которую не будут оценивать с точки зрения недостаточной степени качества жизни.

Сквозь социальные описания нозологии всегда проглядывает своеобразный «лик» вечности, преподнесенный современному человеку в образе генетического кода. Он преподносится как основание его идентичности, некая устойчивость его бытия, не зависящая от трансформаций социального мира. И каким бы человек ни был, отражаясь во взгляде другого то в роли обычного ученика, то в образе успешного карьериста, медицина постоянно будет сталкивать его с генетическим, информационным образом самости. Он и смертен и бессмертен. Его можно запросто стереть или записать на диск, передать потомству, изменить, подкорректировать, улучшить, увековечить, предать огласке или осудить за несовершенство.

Особое место в дискурсе о неидентичности уделяется орфанным (редким) заболеваниям. В отношении большинства из них не существует разработанного лечения, либо оно является чрезвычайно дорогостоящим и не обеспечивает приемлемого качества жизни таким больным. В этой связи все чаще обсуждаются казусы, связанные с исками в судебные инстанции на врачей, допустивших причинение вреда ребенку, страдающему таким заболеванием.

При этом врачи могут обвиняться в недостаточном или ложном информировании о рисках рождения ребенка с тем или иным генетическим заболеванием. Предполагается, что они при эффективном применении генетических технологий могли бы существенным образом снизить риск причинения вреда.

Однако в контексте обсуждения проблемы неидентичности подчеркивается, что обвинение врачей в халатности или бездействии фактически означает обвинение акта существования того или иного ребенка. При их отсутствии данное человеческое существо просто не могло бы появиться на свет.

В логике проблемы неидентичности неизбежно возникает вопрос о том, какое качество жизни следует считать недостойным тому, чтобы жить, или какое качество будущей жизни стоит рассматривать с точки зрения права индивида (будущей матери) на совершение аборта. Как вообще определить норму в медицине? Какие пороги у этой нормы? Какова степень обоснованности этой нормы для врачебного сообщества, пациентов и членов их семей, будущих поколений, государства, которое несет на себе нагрузку сферы здравоохранения?

Усиливающийся процесс генетизации, расширение влияния генетики на все сферы человеческой жизни, с одной стороны, указывает на многообещающий прорыв в области генетических технологий, но с другой - на появление новых форм стигматизации по генетическим признакам, на зарождение неоевгеники. 
Так, Р. Л. Левин и П. С. Миллер выделяют две основные угрозы для сообщества инвалидов, связанные с использованием достижений генетики в медицинских целях: «Во-первых, сообществу инвалидов не хватает голоса на арене генетической политики. Во-вторых, генетические исследования часто направлены на устранение проявлений инвалидности, которые естественным образом возникают в популяции. Это приводит к тому, что люди с ограниченными возможностями рассматривают генетическую революцию как разработанную для предотвращения рождения таких людей, как они. Ученые, воодушевленные открытиями генетики, могут забыть, что жизнь с инвалидностью может быть богатой и приносить удовлетворение. “Здоровье” является субъективной характеристикой, которая чаще всего определяется специалистами в области здравоохранения, учеными и страховой отраслью, а не людьми с ограниченными возможностями» (Miller, Levine, 2013: 95-96).

Подозрительность по отношению к новому - характерная черта человеческого развития. Инновация всегда в той или иной мере порождает стратификацию общества, как бы выделяя тех, кто получает выгоды от ее развития и тех, кто оказывается в уязвимом положении, отброшен в сторону в связи с невозможностью или нежеланием (например, по мировоззренческим причинам) воспользоваться ее благами. Фобии, возникающие в связи с развитием персонализированной медицины, имеют отношение к процессу создания инновационных индивидуализированных лекарственных средств и индивидуальных рекомендаций на основе знания генетического профиля пациента, в частности, осознания невозможности создания лекарств для определенных групп пациентов и в определенном смысле исключения их из поля внимания медицины. Так сейчас, например, оказываются исключены пациенты, являющиеся носителями орфанных (редких) заболеваний, создание лекарств для лечения которых очень часто связано с дефицитом ресурсов общественного здравоохранения.

Выше в контексте проблемы неидентичности поднимался вопрос о том, причиняет ли вред родитель своему ребенку, если знает о наличии у плода патологии и связанных с ней рисках. Абстрактный уровень рассуждений, свойственный философской мысли, зачастую склонен элиминировать значимые факторы эмпирического мира, влияющие на процесс принятия решений. Логическое пространство рассуждений зачастую оказывается универсальным исключительно для системы мышления или этического универсума, выстроенного под задачи самого философа и поэтому игнорирующего проблемы, которые могут быть эксплицированы в рамках концептуальных рассуждений другого типа, другой логики и не охваченных до этого эмпирических фактов.

В том случае, когда в рамках абстрактных рассуждений о неидентичности однозначно утверждается о ненанесении вреда будущему ребенку в связи с игнорированием прогнозов медицинских генетиков, выражающемся либо в 
отказе от прерывания беременности, либо в приеме необходимых лекарств или соблюдении диеты, игнорируются факты о возможности физической и психической адаптации данного индивида к среде, в которой ему предстоит развиваться, не принимаются во внимание возможности родителей этого индивида по оказанию ухода за этим ребенком и экономическую готовность государства обеспечивать такое человеческое существование данного индивида, чтобы оно каждый момент времени не уподоблялось акту борьбы со смертью.

И если в рамках обсуждения проблемы неидентичности отстаивается темпоральность (моменты времени - зачатия и рождения), дающая возможность именно этому индивиду при всех сложностях и проблемах его дальнейшей жизни появиться на свет, то на другую чащу весов зачастую ставится длящаяся темпоральность, которая может стать онтологическим приговором, т. е. время бесконечного страдания и борьбы за жизнь, время безысходного существования, не приносящего чувства жизни, но создающего прецедент пролонгированного умирания.

В 2004 г. громкий отклик получило дело девочки-инвалида Эшли. Родители Эшли, имевшей глубокие нарушения развития, обратились за медицинской помощью, чтобы помочь сохранить их дочь маленькой и, предотвратить ее рост и сексуальное развитие в целях облегчения дальнейшего ухода за ней (Gunther, Diekema, 2006). Родители просили назначить их дочери высокие дозы гормонов и удалить ее грудь и матку, чтобы она оставалась маленькой и с легким весом. Так называемое «лечение Эшли» врачи проводили в детской больнице в Сиэтле, штат Вашингтон.

Случай Эшли показал, как в ситуации дефицита экономии ресурсов и мышления, начинают работать не социальные механизмы помощи, а евгенические механизмы отбора, в результате которых индивидуализированное лечение может принять устрашающую форму персональной дискриминации. Этот пример обнажил этически уязвимую точку пересечения возможностей науки и медицины и существующего социального заказа (со стороны медиков, родителей и части общества) на такого рода манипуляции, а также вскрыл проблему ограниченности ресурсов (и физических, и материальных) для обеспечения адекватной помощи больным.

Случай Эшли не является единичным, он, скорее, отражает общую тенденцию формирования евгенических медицинских фильтров для получения нормализованного по многим параметрам индивида. Нормализация Эшли состояла в отсечении всего лишнего, что может усложнить за ней уход. Медицинская нормализация другого рода состоит в отсечении самой возможности появления индивидов, подобных Эшли, т. е. в избавлении потомства с такими нежелательными чертами и потенциальными проблемами со здоровьем, по отношению к которым достаточно сложно, невозможно или экономически 
нецелесообразно будет подобрать персонализированное лечение (а именно экономический критерий рассматривается как один из ведущих для принятия новой парадигмы медицины) (Попова, 2020: 276-277; см. также: Попова, 2019).

Медицинская нормализация в контексте инновационного развития может быть связана с инструментализацией человеческого существования, преодолением кантианского отношения к человеку как к цели в себе. В современной научной ситуации общество все чаще имеет дело с конвергенцией между экспериментальными научными методами и открытой экспериментальной этикой (этикой, не дающей готовых ответов относительно правильности / неправильности совершаемых действий, испытывающей кризис в трактовке благого и преступного и зависящей от конвенциональных решений относительно проблемы границ человеческого / нечеловеческого).

Индивидуализированное лечение, направленное на решение проблем очень незначительного числа пациентов, страдающих орфанными заболеваниями, является лечением, сопровождаемым индивидуализированной этикой, поскольку универсальные этические нормы, имеющие дело с «нормализованными» человеческими существами, прекращают здесь свое действие. Лечение, не укладывающихся в среднестатистическую норму болезней предполагает разработку норм столь же не стандартной этики.

\section{БИОСОЦИАЛЬНОСТЬ В РОССИИ: ОСОБЫЕ ПРОБЛЕМЫ «ОСОБЫХ» ПАЦИЕНТОВ}

В Российской Федерации существует огромная потребность в изучении заявленной темы. С 2011 г. в российском правовом поле закрепилось понятие «орфанные заболевания», произошла его проблематизация в научном дискурсе. Исследование самоорганизации российских пациентов с орфанными заболеваниями, объединение их в группы для оказания социальной и психологической помощи и формирование биоидентичностей по генетическим признакам представляет собой пример биологической стратификации в российском социуме и возникновения новых форм идентичности, где генетические различия играют определяющую роль. Теоретическое осмысление данных явлений представляет особую актуальность с целью выстраивания широкого диалога между пациентами, представителями пациентских организаций, медицинским сообществом и государством, позволяющим обеспечить своевременные меры социальной поддержки таких пациентов. Огромную роль в этом процессе играет психологический настрой самих пациентов и их близких.

Г. Московцев, автор книги «Я дышу», посвященной пациентам, страдающим муковисцидозом, разрабатывает психологические правила жизни с этой болезнью. Они могут рассматриваться в качестве основополагающих принци- 
пов биосоциальных групп пациентами с редкими заболеваниями. Среди этих принципов следующие: «объединяйтесь», «действуйте», «воспринимайте других менее критично, будьте снисходительны», «не воюйте с миром, а живите с ним в мире» (Московцев, 2013: 356). Среди этих принципов есть и «особые», нацеленные именно на пациентов с муковисцидозом, например, «станьте пропагандистом жизни с муковисцидозом» (там же).

В книге заложен очень важный посыл, связанный с необходимостью реализации стратегии объединения, конвергенции усилий в разных направлениях: «Помогайте друг другу, и человечество будет совершенствоваться, становиться лучше и прочнее. Будет увеличиваться количество связей, переплетений, контактов между его клеточками-людьми... При прочной системе взаимосвязей целостный организм будет работать много эффективнее и существовать дольше» (там же).

За время формирования политики в области орфанных заболеваний было создано множество пациентских организаций и благотворительных фондов, осуществляющих поддержку пациентов с отдельными нозологиями.

Среди них - Союз семей пациентов с гликогеновой болезнью, Российская ассоциация порфирии, Ассоциация содействия больным синдромом Ретта, Союз пациентов с болезнью Гоше и др. Данные сообщества, как правило, являют собой пример успешной самоорганизации пациентов-носителей орфанных заболеваний, их родных и близких.

Также в России стали появляться общественные структуры, имеющие более универсальный характер, охватывающие пациентов со всеми орфанными нозологиями, например, Союз пациентов и пациентских организаций по редким заболеваниям и Всероссийское общество орфанных болезней. Последняя из упомянутых организаций создавалась с целью наиболее полного медицинского информирования пациентов, предоставления им полной картины заболевания.

Эта задача соответствует распространенной во всем мире практике создания информационных порталов, аккумулирующих информацию по редким заболеваниям. Например, одним из наиболее известных порталов такого рода в Европе является многоязычный портал «Орфанет», охватывающий практически все европейские страны (Orphanet, б/д: Электронный ресурс). Также огромную популярность приобрела платформа EURORDIS (EURORDIS, б/д: Электронный ресурс).

Кроме того, благотворительные организации могут осуществлять и другие проекты поддержки пациентов: выпускать журналы, информационные материалы, брошюры, давать консультации по телефону. Организации российских пациентов, выдвигая четкие требования по охране здоровья граждан, зачастую добиваются значительных результатов в получении государственной 
и общественной поддержки в дорогостоящем лечении орфанных заболеваний, необходимой психологической помощи и обретения новых социальных перспектив.

Кроме чисто информационных задач благотворительные организации выполняют функцию привлечения внимания общественности к проблеме редких заболеваний. С этой целью организовываются фестивали (стоит упомянуть фестиваль-конкурс «Редкий фестиваль»), работает онлайн-канал «Редкое телевидение» и издается «Редкий журнал». В названиях подобных проектов, осуществляемых при поддержке Союза пациентов и пациентских организаций по редким заболеваниям, неявно скрывается сконструированная лингвистическими средствами самоидентификация орфанных пациентов: тяжелые нозологии стараются отчасти компенсировать с помощью языка, подчеркивая уникальность пациента, «редкость» его биологической идентичности. «Особая» идентичность выстраивается особыми лингвистическими средствами.

Сложившиеся в России различные формы «орфанной» биосоциальности между тем так и не стали предметом специального этико-социального и философско-методологического анализа. Формирование базы знаний об орфанных (редких) заболеваниях и особенностях самоорганизации пациентов, страдающих подобными болезнями, определение связи таких феноменов, как генетизация, биосоциальность и биоидентичность, на наш взгляд, будет способствовать конвергенции общественных усилий в отношении защиты прав пациентов и формировать необходимые меры их поддержки.

\section{ЗАКЛЮЧЕНИЕ}

Развитие генетических технологий принесло современному человеку новое знание, связанное с генетическими характеристиками человека, его персональной генетической информацией. Полученное знание все чаще рассматривается в качестве основания стратификации индивидов с целью дальнейшего лечения и выбора траектории помощи пациенту, в том числе оказания ему не только медицинской, но и социальной поддержки. Так, современная индивидуализированная (персонализированная) медицина имеет дело с теми группами пациентов, для которых существует лечение и в меньшей - с теми пациентами, которым науке и медицине на данном этапе их развития предложить пока нечего.

В последнем случае генетизация приобретает вполне очевидные евгенические коннотации, оказывая влияние на процесс принятия решения о рождении / нерождении ребенка и в целом на проектирование желанного / нежеланного образа человечества. Так, неблагоприятный прогноз относительно здоровья плода подразумевает определенную ментальную категоризацию по нозологии, способу ведения родов, выбору дальнейшей медикаментозной и 
психологической поддержки матери и ребенка, но и может также способствовать развитию практики элиминации плода.

Феномен генетизации, таким образом, отражает не просто информирование о диагнозе и рисках, но и порождает определенные стратегии толкования, их интерпретации, имеющие отношение к праву на жизнь или смерть. Они формируют траектории развития человека и его судьбу и оказывают психологическое давление на процесс принятия решения. В горизонте человеческих ожиданий, а впоследствии и на практике проводится категоризация пациентов и их близких не только по медицинским, но и, в конечном итоге, по этическим критериям.

В свете этих проблем рассмотренный нами феномен образования биосоциальных групп является своего рода компенсационным механизмом, позволяющим индивиду отчасти устранять негативное давление генетизации. В то же время феномен биосоциолизации необходимо рассматривать комплексно, учитывая как ее положительные, так и теневые стороны. Процесс биосоциализации, позволяющей выделять пациентов в группы, сформированные по генетическому признаку, не должен стать альтернативой общей социализации и приводить к минимизации социальности, замыканию пациента на своей болезни в пределах своей группы, к своего рода онтологическому карантину, невозможности полного взаимодействия с социумом. Немаловажными здесь являются расширение спектра возможностей пациентов с орфанными заболеваниями и создание соответствующей социальной инфраструктуры как необходимой для обеспечения приемлемого качества жизни пациентов с орфанными заболеваниями биополитической траектории.

\section{СПИСОК ЛИТЕРАТУРЫ}

EURORDIS (б/д) [Электронный ресурс]. URL: https://www.eurordis.org/ $\underline{\mathrm{ru}}$ [архивировано в WaybackMachine] (дата обращения: 20.06.2020).

Московцев, Г. Н. (2013) Я дышу, или Муковисцидоз изнутри. СПб. : Питер. 381, [4] c.

Попова, О. В. (2019) Орфанные заболевания: локусы биосоциальности и нормативные практики // Человек. Т. 30. № 6. C. 156-173. DOI: 10.31857/ S023620070007678-2

Попова, О. В. (2020) Тело как территория технологий: от социальной инженерии к этике биотехнологического конструирования. М. : «Канон+» РООИ «Реабилитация». 352 c.

Dimond, R., Bartlett, A., Lewis, J. (2015) What binds biosociality? The collective effervescence of the parent-led conference // Social Science \& Medicine. Vol. 126. P. 1-8. DOI: 10.1016/j.socscimed.2014.12.005 
Gunther, D. F., Diekema, D. S. (2006) Attenuating growth in children with profound developmental disability: A new approach to an old dilemma // Archives of Pediatrics \& Adolescent Medicine. Vol. 160. No. 10. P. 1013-1017. DOI: $\underline{10.1001 / \text { archpedi.160.10.1013 }}$

Lippman, A. (1992) Led (astray) by Genetic Maps: The cartography of the human genome and health care // Social Science \& Medicine. Vol. 35. Issue 12. P. 1469-1476. DOI: $\underline{10.1016 / 0277-9536(92) 90049-\mathrm{V}}$

Miller, P. S., Levine, R. L. (2013) Avoiding genetic genocide: understanding good intentions and eugenics in the complex dialogue between the medical and disability communities // Genetics in Medicine. Vol. 15. Issue 2. P. 95-102. DOI: 10.1038/gim.2012.102

Orphanet (б/д) [Электронный pecypc]. URL: https://www.orpha.net/ [архивировано в WaybackMachine] (дата обращения: 20.06.2020).

Parfit, D. (1987) Reasons and persons. Oxford : Clarendon Press. xv, 543 p.

Rabinow, P. (1992) Artificiality and enlightenment: From sociobiology to biosociality // Incorporations / ed. by J. Crary, S. Kwinter. N. Y. : Zone Books. 633 p. P. 234-252.

Singer, M. et al. (2017) Syndemics and the biosocial conception of health / M. Singer, N. Bulled, B. Ostrach, E. Mendenhall // The Lancet. Vol. 389. Issue 10072. P. 941-950. DOI: $10.1016 / \mathrm{s} 0140-6736(17) 30003-\mathrm{X}$

Дата поступления: 15.07.2020 г.

\section{REFERENCES}

EURORDIS (s.d.) [online] Available at: https://www.eurordis.org/ru [archived in WaybackMachine] (accessed 20.06.2020). (In Russ.).

Moskovtsev, G. N. (2013) Ia dyshu, ili Mukovistsidoz iznutri [I breathe, or Cystic fibrosis from the inside]. St. Petersburg : Piter Publ. 381, [4] p. (In Russ.).

Popova, O. V. (2019) Orfannye zabolevaniia: lokusy biosotsial'nosti i normativnye praktiki [Orphan diseases: Biosocial loci and regulatory practices]. Chelovek, vol. 30, no. 6, pp. 156-173. (In Russ.). DOI: 10.31857/S023620070007678-2

Popova, O. V. (2020) Telo kak territoriia tekhnologii: ot sotsial'noi inzhenerii $k$ etike biotekhnologicheskogo konstruirovaniia [The body as a territory of technology: From social engineering to the ethics of biotechnological design] : a monograph. Moscow : Kanon+ Publ., RPOD "Reabilitatsiia”. 352 p. (In Russ.).

Dimond, R., Bartlett, A. and Lewis, J. (2015) What binds biosociality? The collective effervescence of the parent-led conference. Social Science \& Medicine, vol. 126, pp. 1-8. DOI: $10.1016 /$ j.socscimed.2014.12.005

Gunther, D. F. and Diekema, D. S. (2006) Attenuating growth in children with profound developmental disability: A new approach to an old dilemma. Archives of 
Pediatrics \& Adolescent Medicine, vol. 160, no. 10, pp. 1013-1017. DOI: $10.1001 /$ archpedi.160.10.1013

Lippman, A. (1992) Led (astray) by Genetic Maps: The cartography of the human genome and health care. Social Science \& Medicine, vol. 35, issue 12, pp. 1469-1476. DOI: $10.1016 / 0277-9536(92) 90049-\mathrm{V}$

Miller, P. S. and Levine, R. L. (2013) Avoiding genetic genocide: understanding good intentions and eugenics in the complex dialogue between the medical and disability communities. Genetics in Medicine, vol. 15, issue 2, pp. 95-102. DOI: 10.1038/gim.2012.102

Orphanet (s.d.) [online] Available at: https://www.orpha.net/ [archived in WaybackMachine] (accessed 20.06.2020).

Parfit, D. (1987) Reasons and persons. Oxford : Clarendon Press. xv, 543 p.

Rabinow, P. (1992) Artificiality and enlightenment: From sociobiology to biosociality. In: Incorporations / ed. by J. Crary and S. Kwinter. New York : Zone Books. 633 p. Pp. 234-252.

Singer, M. et al. (2017) Syndemics and the biosocial conception of health / M. Singer, N. Bulled, B. Ostrach and E. Mendenhall. The Lancet, vol. 389, issue 10072, pp. 941-950. DOI: 10.1016/s0140-6736(17)30003-X

Submission date: 15.07.2020.

Попова Ольга Владимировна - доктор философских наук, ведущий научный сотрудник, руководитель сектора гуманитарных экспертиз и биоэтики Института философии РАН. Адрес: 109240, Россия, г. Москва, ул. Гончарная, д. 12, стр. 1. Тел.: +7 (495) 697-90-67. Эл. адрес: J-9101980@yandex.ru

Popova Olga Vladimirovna, Doctor of Philosophy, Leading Researcher, Head of the Sector for Humanitarian Expertise and Bioethics, Institute of Philosophy, Russian Academy of Sciences. Postal address: Bldg. 1, Goncharnaya St., 12, 109240 Moscow, Russian Federation. Tel.: +7 (495) 697-90-67. E-mail: J-9101980@yandex.ru

Попов Владимир Викторович - студент Инженерно-физического института биомедицины Национального исследовательского ядерного университета «МИФИ». Адрес: 115409, Россия, г. Москва, Каширское ш., 31. Эл. адрес: popovvladimir618618@gmail.com

Popov Vladimir Viktorovich, Student, Institute of Engineering Physics for Biomedicine, National Research Nuclear University MEPhI (Moscow Engineering Physics Institute). Postal address: 31, Kashirskoye shosse, 115409 Moscow, Russian Federation. E-mail: popovvladimir618618@gmail.com 
Для изитирования:

Попова O. B., Попов В. В. Биосоциальность, генетизация, биоидентичность: социально-философский взгляд [Электронный ресурс] // Горизонты гуманитарного знания. 2020. № 4. C. 35-51. URL: https://journals.mosgu.ru/ggz/ article/view/1306 (дата обращения: дд.мм.гггг). DOI: 10.17805/ggz.2020.4.3 